\title{
Influence of Landscape Coverage on Measuring Spatial and Length Properties of Rock Fracture Networks: Insights from Numerical Simulation
}

\author{
Wenzhuo CaO ${ }^{1}$ and Qinghua LeI ${ }^{1}$ (D)
}

\begin{abstract}
Natural fractures are ubiquitous in the Earth's crust and often deeply buried in the subsurface. Due to the difficulty in accessing to their three-dimensional structures, the study of fracture network geometry is usually achieved by sampling two-dimensional (2D) exposures at the Earth's surface through outcrop mapping or aerial photograph techniques. However, the measurement results can be considerably affected by the coverage of forests and other plant species over the exposed fracture patterns. We quantitatively study such effects using numerical simulation. We consider the scenario of nominally isotropic natural fracture systems and represent them using 2D discrete fracture network models governed by fractal and length scaling parameters. The groundcover is modelled as random patches superimposing onto the $2 \mathrm{D}$ fracture patterns. The effects of localisation and total coverage of landscape patches are further investigated. The fractal dimension and length exponent of the covered fracture networks are measured and compared with those of the original non-covered patterns. The results show that the measured length exponent increases with the reduced localisation and increased coverage of landscape patches, which is more evident for networks dominated by very large fractures (i.e. small underlying length exponent). However, the landscape coverage seems to have a minor impact on the fractal dimension measurement. The research findings of this paper have important implications for field survey and statistical analysis of geological systems.
\end{abstract}

Key words: Landscape, natural fracture network, outcrop mapping, fractal dimension, length distribution.

\section{Introduction}

Fractures such as faults, joints and veins are ubiquitous in crustal rocks. These naturally occurring discontinuities often form complex, hierarchical

1 Department of Earth Science and Engineering, Imperial College London, London SW7 2AZ, UK. E-mail: q.1ei12@imperial.ac.uk networks over a broad range of length scales, and dominate the bulk behaviour of geological media (Bonnet et al. 2001). It is, therefore, important to understand and characterise the distribution of natural fractures in geological formations, which is relevant to a variety of engineering applications such as hydrocarbon extraction, geothermal production, groundwater remediation and geological disposal of radioactive waste (Rutqvist and Stephansson 2003; Lei et al. 2017).

However, natural fractures are often deeply buried in the Earth's crust. It is very difficult to perform an accurate and complete measurement of the three-dimensional (3D) structure of a natural fracture system. The study of fracture network geometries is thus usually achieved by sampling their two-dimensional (2D) exposures at the Earth's surface using various field mapping techniques. Trace-line maps of fracture networks at the metre scale are conventionally mapped from analogue drawings at ground level or field photographic surveys of exposed rock surfaces. Since the 1940s, the aerial photography technique has been employed to map geological structures for interpretation (Eardley 1942; Pillmore 1957). Aerial photographs are instantaneous records of ground details taken at heights ranging from tens of meters to hundreds of kilometres using, e.g. airplanes (Reed 1940; Ray 1984), helicopters (Odling 1997), or satellites (Holland et al. 2009; Bertrand et al. 2015). This technique allows researchers to capture geological features at different length scales, especially those large-scale structures (Maerten et al. 2001; Watkins et al. 2015). It can also help identify anomalous areas that need further detailed field mapping, and eliminate or reduce the survey tasks in certain regions (Ray 1984). For higher spatial 
resolutions, remote controlled yet low cost facilities including balloons (Odling 1997) and kites (Smith et al. 2009) could be utilised for the collection of aerial images at low flying heights, e.g. tens of meters above rock surfaces. The recent unmanned aerial vehicles (UAV) combined with digital photogrammetry are increasingly deployed to obtain aerial photographs in short time intervals with high resolutions (Bemis et al. 2014; Clapuyt et al. 2016; Cawood et al. 2017). These photographs can have a resolution at centimetre to millimetre scales, which can significantly improve the acquisition of geometric and structural information (Vollgger and Cruden 2016). Thus, ground-based and aerial photogrammetry in combination provides a multi-scale, highresolution tool for collecting geological data (Bemis et al. 2014).

By analysing the samples of outcrop mapping, many important geometrical properties of natural fracture systems can be studied including their density, spacing, spatial organisation, and length distribution (Odling 1992, 1997; Bonnet et al. 2001; Bour et al. 2002; Lei and Wang 2016). However, the quality of photogrammetric measurements is often affected by groundcover effects due to the presence of forests and other plant species over the Earth's surface (Belayneh et al. 2009; Le Garzic et al. 2011). This may result in some biases in the measurement of fracture network geometries, such as an exaggeration of clustering behaviour, an underestimation of fracture density, and superficial truncation of large fractures (Lei and Wang 2016). Figure 1 shows a few examples of fracture patterns reported in the literature, in which the landscape coverage effects seem not trivial (Ghosh and Daemen 1993; Rawnsley et al. 1998; Gillespie et al. 2001; Bisdom et al. 2017).

Landscapes are defined as the spatially heterogeneous geographic areas composed of clusters of interacting ecosystems, such as natural terrestrial systems ranging from forests to grasslands (Turner et al. 2001). Landscape patterns are formed as a result of interactions between tectonic, lithologic and climatic factors: tectonism constructs landscapes through crustal movement such as uplift and warping; lithology influences landscape evolution by dominating erodibility of underlying rock or soil; climatic parameters degrade landscapes through physical and chemical erosion through wind and water (Krummel et al. 1987; Lifton and Chase 1992). In addition, landscape spatial distribution is affected by biota and human activities such as urbanisation, agriculture and forestry (Krummel et al. 1987). The resulting landscape is a mixture of natural and anthropogenic land cover patches of different sizes and shapes (Krummel et al. 1987). The landscape patterns evolve over time and vary in spatial distribution (Turner and Rusher 1988), and their geometrical complexity may be described by fractal geometry (Mandelbrot and Pignoni 1983). Krummel et al. (1987) first used a perimeter-area method to evaluate the fractal dimension of deciduous forest patterns in a region which experienced extensive alteration of forest cover to cropland. Natural landscapes generally exhibit distinctive fractal features over a range of scales from hundreds of metres to kilometres (Lifton and Chase 1992). Little is known about how fractal landscape patterns were produced in a composite of complicated natural and human processes (Xu et al. 1993). However, the fractal dimension is considered to be a very useful parameter for interpreting the heterogeneous features and modelling the spatial distribution of landscapes (Gardner et al. 1987; Turner et al. 1989).

The objective of this study is to investigate whether and how landscape coverage and its spatial distribution affect the measurement of the spatial and length properties of natural fracture networks. We consider the scenario of nominally isotropic natural fracture systems, in which fractures are uniformly oriented, whereas the cases of anisotropic fracture networks with distinct fracture sets will be addressed in our future research. The rest of the paper is organised as follows. In Sect. 2, discrete fracture networks governed by different combinations of fractal dimension and power law length exponent values are generated, and subsequently covered by fractal landscape patterns constrained by various fractal dimensions and coverage ratios. The statistical properties of landscape-covered fracture network patterns are then measured. In Sect. 3, the simulation results about the effects of landscape fractal dimension and coverage ratio on measuring statistical properties of fracture networks are presented. Finally, a short discussion is given and conclusions are drawn. 
(a)
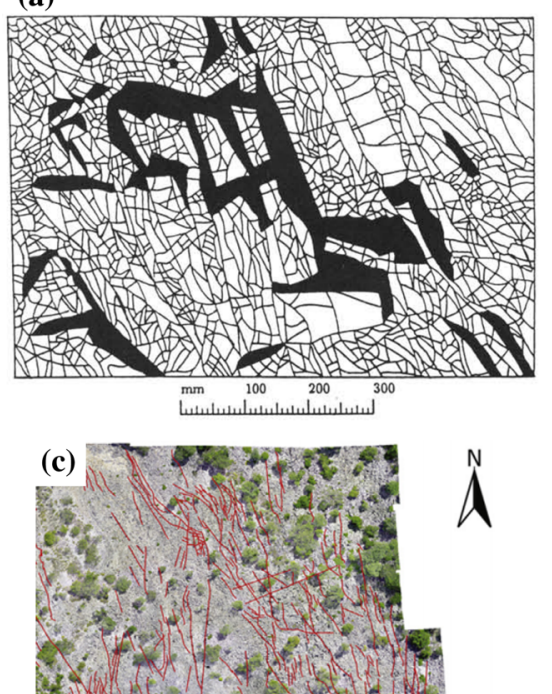

(b)

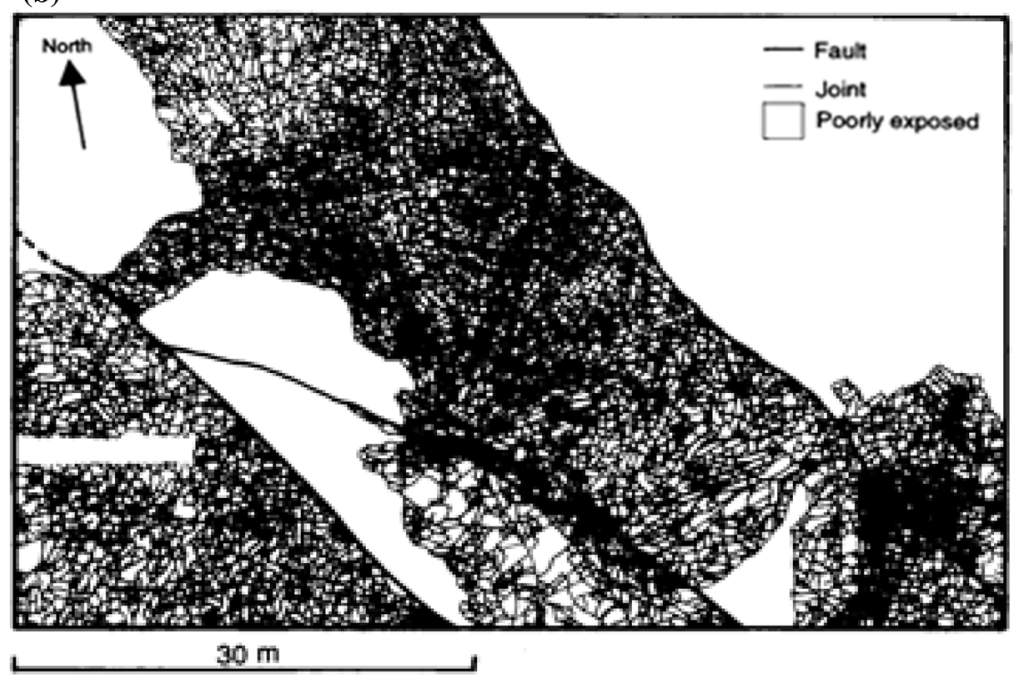

(d)
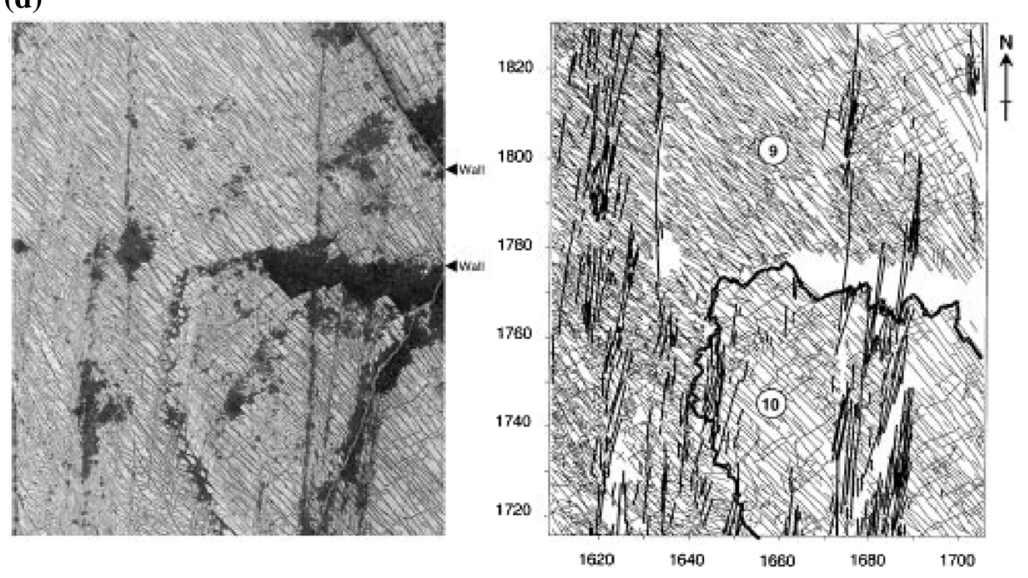

Figure 1

Examples showing the landscape coverage effects on mapping fracture network outcrops from photographs: a joint trace map from a photograph of a bench face (Ghosh and Daemen 1993), b line drawings of joints in an area on the edges of the Bristol Channel Basin (Rawnsley et al. 1998), $\mathbf{c}$ digitised fracture network using aerial photography in the Jandaíra Formation (Bisdom et al. 2017), and $\mathbf{d}$ aerial photograph and mapped fractures in the same area in Cappanawalla (Gillespie et al. 2001)

\section{Methodology}

\subsection{Statistical Model of Fracture Networks}

Extensive field observations suggest that fracturing occurs at all scales in the crust and creates hierarchical structures that exhibit long-range correlations from macroscale frameworks to microscale fabrics (Allegre et al. 1982; Barton 1995). The spatial organisation of natural fracture networks can be characterised by the fractal dimension $D$, which quantifies the manner whereby fractals cluster and spread in the Euclidean space and can be measured using the box-counting method (La Pointe 1988; Chilès 1988; Ehlen 2000) or the two-point correlation function (Hentschel and Procaccia 1983; Bour and Davy 1999). The density distribution of fracture lengths can be described by a statistical model as given by (Bour et al. 2002; Davy et al. 2010):

$$
n(l, L)=\alpha L^{D} l^{-a}, l \in\left[l_{\min }, l_{\max }\right]
$$


where $n(l, L) \mathrm{d} l$ gives the number of fractures with sizes belonging to the interval $[l, l+\mathrm{d} l](\mathrm{d} l \ll l)$ in an elementary volume of characteristic size $L, a$ is the power law length exponent, $\alpha$ is the density term, and $l_{\min }$ and $l_{\max }$ are the smallest and largest fracture sizes. The density term $\alpha$ is related to the total number of fractures in the system and varies as a function of fracture orientations (Davy et al. 2010). The length exponent $a$ defines the relative proportion of large and small fractures (Davy 1993; Pickering et al. 1995). The extent of the power law relation is bounded by an upper limit $l_{\text {max }}$ that is probably related to the thickness of the crust, and a lower limit $l_{\min }$ that is constrained by a physical length scale (e.g. grain size) or the resolution of measurement (Bonnet et al. 2001). For numerical simulations, the model size $L$ usually meets $l_{\text {min }} \ll L \ll l_{\text {max }}$ (Darcel et al. 2003).

In theory, $D$ is restricted to the range $[1,2]$ for the $2 \mathrm{D}$ scenario. A $D$ value of 2 represents a homogeneous spatial distribution, i.e. "space filling". As $D$ decreases, the fracture pattern becomes more clustered associated with more empty areas. In theory, $a$ is restricted to $[1, \infty]$ in $2 \mathrm{D}$. A small $a$ value corresponds to a system dominated by large fractures, while $a \rightarrow \infty$ relates to a pattern with all fractures having an equal size (i.e. $l_{\text {min }}$ ). Extensive measurements based on 2D trace maps reveal that generally $D$ varies between $[1.5,2]$ and $a$ falls between [1.3, 3.5] (Bonnet et al. 2001). The $D$ and $a$ values as well as their relationship may control the connectivity, permeability and strength of fractured rocks (Darcel et al. 2003; de Dreuzy et al. 2004; Davy et al. 2006). Thus, it is very important to accurately measure the $D$ and $a$ values of natural fracture networks, the observation of which, however, may be affected by landscape variation.

In the following subsections, discrete fracture networks defined by this power law model are generated and then superimposed by random fractal landscape patterns, with the statistical properties of the original and covered fracture network patterns further compared. Subscripts are used to distinguish statistical properties of different categories, i.e. " $\mathrm{f}$ " for prescribed fracture network patterns, "l" for landscape patterns, and " $\mathrm{m}$ " for measured fracture network patterns affected by groundcovers.

\subsection{Fracture Network Generation}

The spatial distribution of discrete fracture networks governed by a prescribed $D_{\mathrm{f}}$ value could be constructed through a multiplicative cascade process (Darcel et al. 2003). This cascade process is a recursive operation of fragmentation of the model domain into subdomains of identical sizes. For a non-fractal pattern $\left(D_{\mathrm{f}}=2\right)$, which has a uniform spatial distribution, the locations of fracture barycentres are modelled using the Poisson process. For a fractal spatial distribution of fracture barycentres $\left(D_{\mathrm{f}}<2\right)$, a set of non-uniform probabilities of fracture occupancy $P_{i}(i=1, \ldots, n)$ are randomly permuted and assigned to subdomains at each stage of the fragmentation cascade (Fig. 2a-c). We only consider the mono-fractal scenario, and the set of probabilities is related to the fractal dimension and the scale ratio $r$ of the fragmentation process as: $\sum_{i=1}^{n} r^{D_{\mathrm{f}}} P_{i}^{2}=1$. The number of fractures in each subdomain is determined based on the total number of fractures multiplied by the corresponding probability. Within the minimum subdomains, fracture barycentres are randomly distributed regardless of the fractal dimension. An example of fracture barycentres with $D_{\mathrm{f}}=1.5$ generated from 6 cascades is given in Fig. $2 \mathrm{c}$. Fracture orientations are assigned isotropically. Fracture lengths are sampled from a power law distribution constrained by the length exponent $a_{\mathrm{f}}$. Fractal fracture networks governed by different $a_{\mathrm{f}}$ and $D_{\mathrm{f}}$ values can then be generated by synthesising the different geometrical attributes modelled as independent random variables.

In our numerical model, we choose the fracture length bounds, i.e. $l_{\max }$ and $l_{\min }$, to be $50 \times L$ and $L /$ 50 , respectively. The scale ratio $r$ of the fragmentation cascade is chosen to be 2 , and the cascade process is implemented for 6 iterations. A total of 800 fractures with random orientations are generated in the domain. The chosen total number is much larger than the suggested criterion of a minimum of 200 fractures to be sampled (Bonnet et al. 2001) and is thus considered sufficient for statistical analysis. Different combinations of $D_{\mathrm{f}}=1.5,1.75$ and 2, and $a_{\mathrm{f}}=1.5,2.5$ and 3.5 are considered ( 9 scenarios in total), and 10 DFN realisations are generated for each scenario. Figure 3 shows one of the realisations of each different case. 
(a)

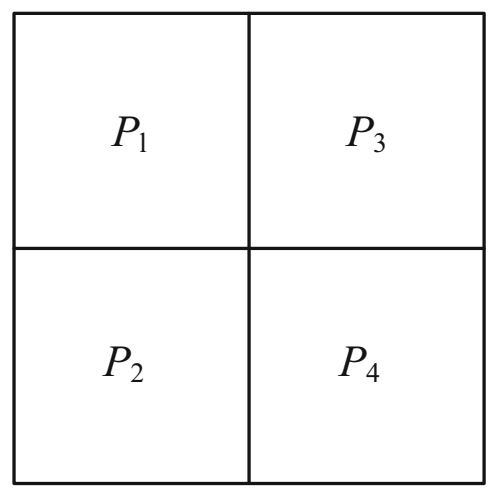

(d)

$\{1, P$ is among the largest $M$ probability values

$\{0, P$ is not among the largest $M$ probability values

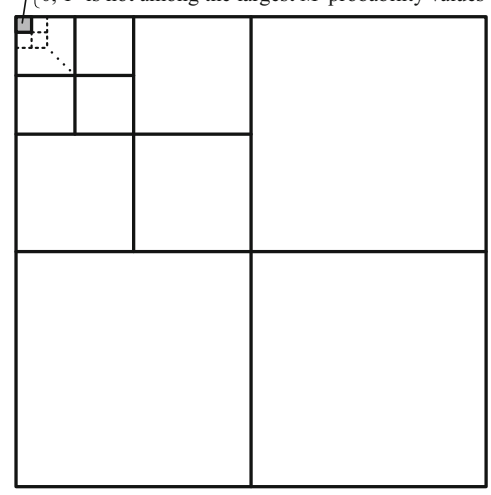

(b)

\begin{tabular}{|l|l|l|l|}
\hline$P_{1} P_{2}$ & $P_{1} P_{3}$ & $P_{3} P_{4}$ & $P_{3} P_{1}$ \\
\hline$P_{1} P_{4}$ & $P_{1} P_{1}$ & $P_{3} P_{2}$ & $P_{3} P_{3}$ \\
\hline$P_{2} P_{3}$ & $P_{2} P_{2}$ & $P_{4} P_{1}$ & $P_{4} P_{3}$ \\
\hline$P_{2} P_{1}$ & $P_{2} P_{4}$ & $P_{4} P_{4}$ & $P_{4} P_{2}$ \\
\hline
\end{tabular}

(e)

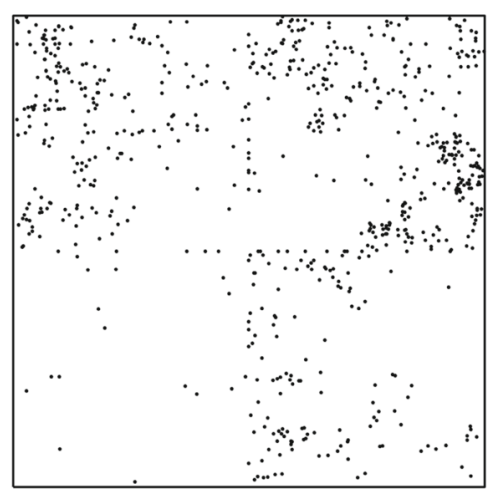

(c) $P=\prod_{i=1}^{n}$ permuation $\left(P_{i}\right)$

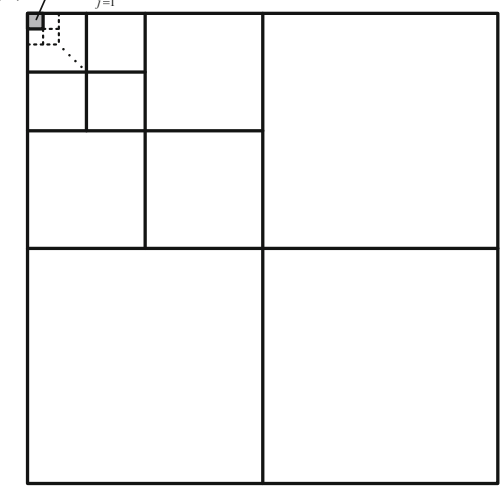

(f)

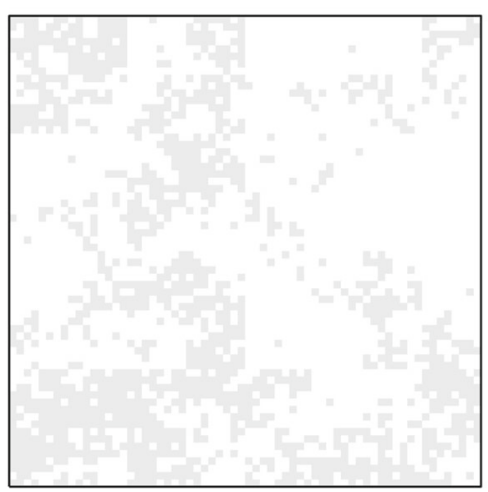

Figure 2

Schematic of the fracture network and landscape pattern generation process: a the 1st and b 2nd iteration of the multiplicative cascade process; the probability field in the $j$ th iteration for $\mathbf{c}$ fracture network generation and $\mathbf{d}$ landscape patch generation; examples showing e barycentres of a fracture network pattern with $D_{\mathrm{f}}=1.5$ and $\mathbf{f}$ a landscape patch pattern with $D_{1}=1.5$

\subsection{Landscape Pattern Generation}

The spatial heterogeneity and evolution of landscapes have been extensively studied in the field of landscape ecology. Gardner et al. (1987) used the percolation theory to construct neutral models to describe landscape spatial distribution in the absence of landscape formation processes. The model quantified landscape patterns based on the fraction of landscape, the linear dimension of the map, and the fractal dimension of landscape clusters. The model was further applied to investigate the spread of ecological disturbance across a landscape (Turner et al. 1989). Milne et al. (1989) developed a spatially neutral model and used Bayesian probabilities conditional on twelve landscape variables to predict deer wintering habitats. Kubo et al. (1996) built a latticestructured model to simulate the spatial expansion, regeneration and closure of gaps in forested ecosystems over time. Wu et al. (2000) conducted scale variance analysis of landscapes using a multiple-scale statistical model with spatial nested hierarchical structures.

Thus, in this paper, we model the landscape pattern as an assembly of small-sized patches, the distribution of which is governed by the landscape fractal dimension $D_{1}$ and a coverage ratio $c$ (i.e. ratio of the groundcover area to the domain area). The fractal landscape map is also constructed using the multiplicative cascade process, which includes the fragmentation cascade and the probability field 

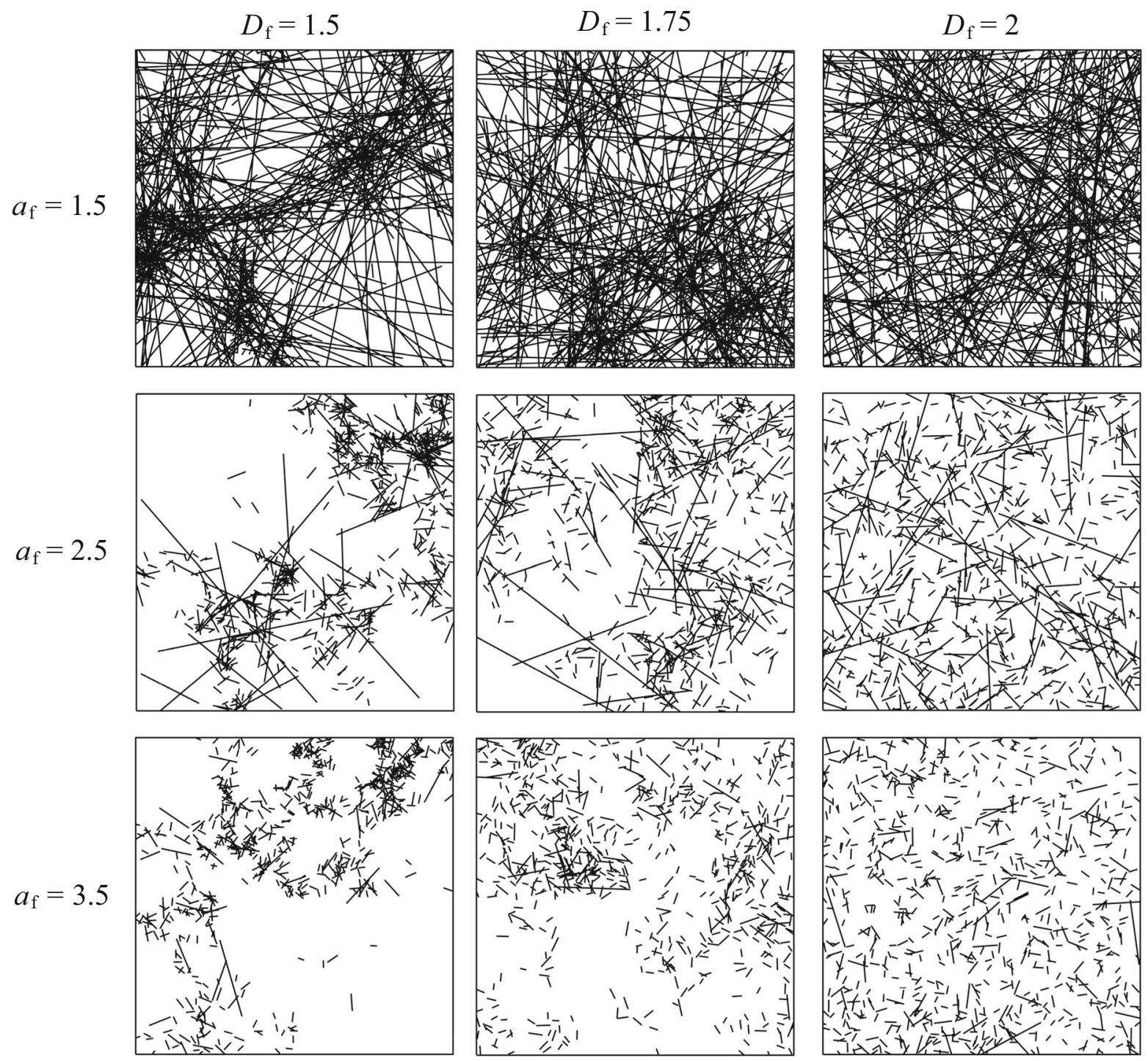

Figure 3

Examples of generated nominally isotropic fracture networks associated with different values of fractal dimension $D_{\mathrm{f}}$ and power law length exponent $a_{\mathrm{f}}$. The total number of fractures is fixed as 800 . The ratio of the minimum fracture length $l_{\min }$ to the domain size $L$ is set as $1 / 50$

calculation. A probability matrix comprising only integers 1 and 0 should subsequently be mapped to the minimal subdomains to indicate landscape occupancy or not, depending on the eventual probability field. Assuming that a total number of $M$ minimal subdomains are required to be covered for a given landscape pattern, elements in the probability matrix corresponding to the largest $M$ values in the eventual probability field are populated with a probability value of 1 , while others are assigned 0 (Fig. 2d). The generated landscape patterns are then superimposed onto the generated fracture network patterns, leading to some of the fracture traces being either truncated (if partially covered) or removed (if completely covered). An example of a landscape pattern with $D_{1}=1.5$ generated from this process is shown in Fig. 2f.

We set the same scale ratio and the number of cascade iterations as those for fracture network generation, which corresponds to a landscape patch 
resolution of $0.78 \times l_{\min }$. For each generated fracture network realisation, ten landscape realisations are generated for each given combination of the landscape fractal dimension $D_{1}=1.5,1.75$ and 2 , and the coverage rate $c=0.1,0.2, \ldots, 0.5$ (i.e. 15 combinations in total). Figure 4 shows the landscape-covered fracture networks as a result of superimposing different fractal landscape patterns onto an original fracture network.

\subsection{Measurement of Statistical Properties}

The statistical properties of landscape-covered fracture networks including the fractal dimension $D_{\mathrm{m}}$ and $a_{\mathrm{m}}$ are further measured. The two-point correlation function is used for measuring the fractal dimension of fracture barycentres. The correlation function $C_{2}(r)$ for $N$ number of fracture barycentres is defined by

$$
C_{2}(r)=2 N_{\mathrm{p}}(r) / N^{2} \sim r^{D_{\mathrm{m}}},
$$

where $N_{\mathrm{p}}(r)$ is the number of pairs of barycentres whose distance is less than $r$ (Bour and Davy 1999). The fractal dimension can be obtained through regression fitting on the bilogarithmic graph. Figure 5a shows the calculation of the fractal dimension of an original fracture network and its landscapecovered networks based on regression fitting and local slope analysis. It can be seen that the fracture network still follows a fractal spatial distribution after landscape coverage.

The power law length exponent $a$ can be derived from the cumulative distribution or density distribution of fracture lengths (Davy 1993; Pickering et al. 1995). Figure $5 \mathrm{~b}$ shows an example of the density distribution of lengths of a fracture network pattern before and after landscape cover of different ratios. The density distribution for different landscape coverage ratios approximately follows a power law relationship, but the fitted curve becomes steeper with increasing landscape coverage, i.e. the length exponent decreases.

\section{Results}

Figures 6 and 7 present the measured fractal dimension $D_{\mathrm{m}}$ and length exponent $a_{\mathrm{m}}$, respectively, of landscape-covered fracture network patterns as a result of superimposing different landscape patterns with different fractal dimension $D_{1}$ and coverage ratio $c$ onto the fracture networks with different underlying fractal dimension $D_{\mathrm{f}}$ and length exponent $a_{\mathrm{f}}$. The measured fractal dimension and length exponent of the original fracture networks (i.e. $c=0$ ) are also presented for reference, and their slight deviation from the input $D_{\mathrm{f}}$ and $a_{\mathrm{f}}$ values is attributed to the boundary censoring operation which deletes the parts of some fractures extending outside the finite-sized domain.

As shown in Fig. 6, the measured $D_{\mathrm{m}}$ of landscape-covered fracture networks varies with the increase of landscape coverage ratio, with the variation trend determined by the properties of the original fracture network and the landscape pattern. The deviation of $D_{\mathrm{m}}$ from the underlying $D_{\mathrm{f}}$ is found to be in the range of $\left|D_{\mathrm{m}}-D_{\mathrm{f}}\right|<0.1-0.2$, which seems larger when $D_{\mathrm{f}}$ is large. The measured $D_{\mathrm{m}}$ of fracture networks superimposed by landscape patterns with $D_{1}=1.5$ and 1.75 are almost indistinguishable for different coverage ratio conditions. The measured $D_{\mathrm{m}}$ values for fracture network patterns covered by nonfractal landscape $\left(D_{1}=2\right)$ are higher than those covered by fractal ones $\left(D_{1}=1.5\right.$ or 1.75$)$, especially when the coverage ratio is high. There is no apparent influence of the prescribed $a_{\mathrm{f}}$ on measured $D_{\mathrm{m}}$ values, indicating that the measured spatial clustering of landscape-covered fracture networks may be independent of the underlying size scaling properties of fractures.

From Fig. 7, it can be seen that the measured length exponent $a_{\mathrm{m}}$ is affected by the groundcover effect, the extent of which depends on the properties of the original fracture network and the landscape pattern. An increased landscape coverage leads to an increase in $a_{\mathrm{m}}$, because the observed fractures are shorter than the original ones due to the presence of groundcover patches. It can be noticed that when $c=0.1$, the deviation of $a_{\mathrm{m}}$ from the underlying $a_{\mathrm{f}}$ is quite small for all cases; however, when $c \geq 0.2$, the difference becomes non-negligible and can even be as large as 1-2 when half of the domain is covered, i.e. $c=0.5$. The measured $a_{\mathrm{m}}$ values for fracture networks affected by non-fractal landscape systems $\left(D_{1}=2\right)$ are much higher than those of the networks 

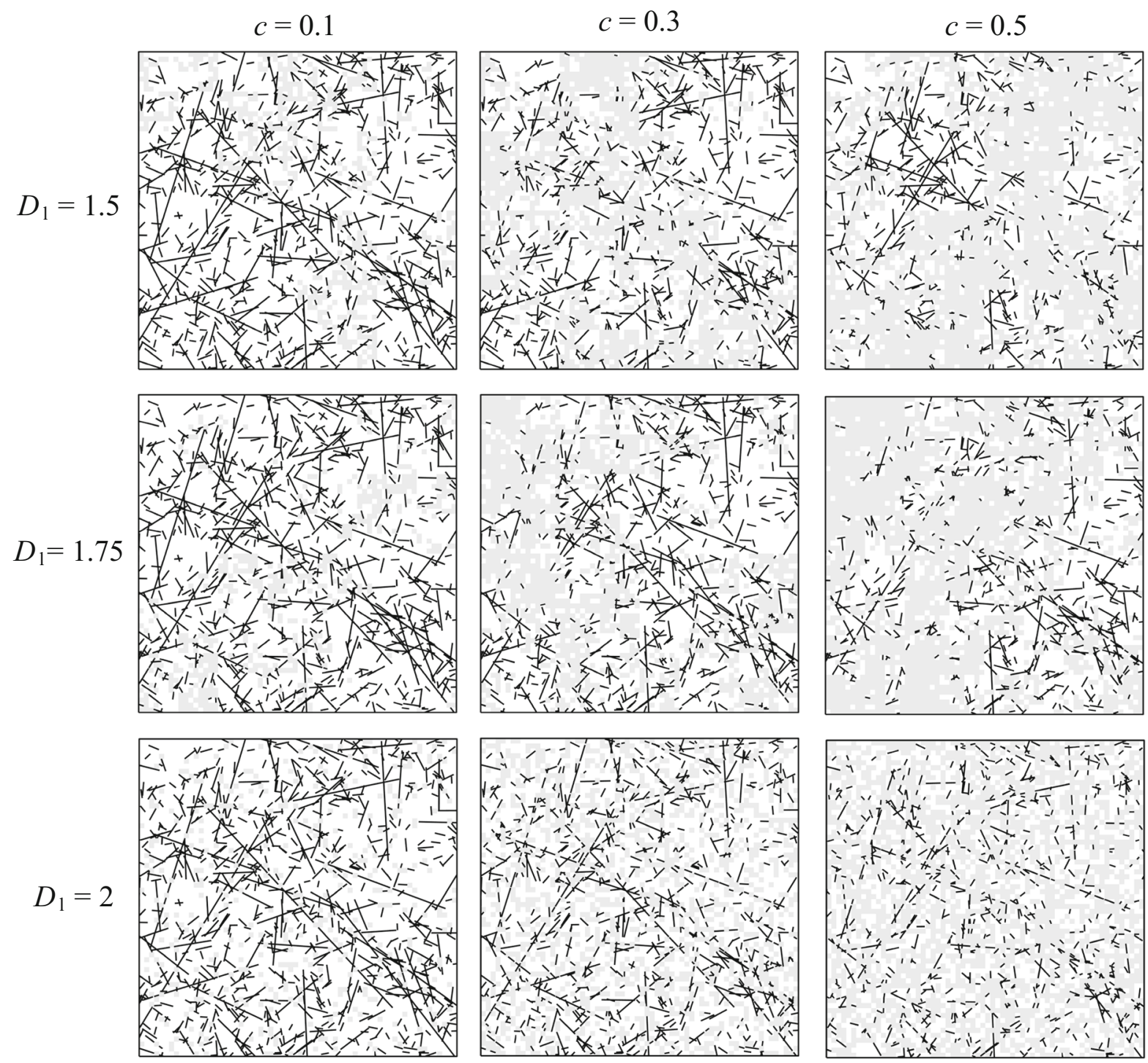

Figure 4

Examples of synthetic landscape-covered fracture network patterns as a result of superimposing landscape patterns with different fractal dimension $D_{1}$ and coverage ratio $c$ onto a fracture network with a fractal dimension $D_{\mathrm{f}}=2$ and a length exponent $a_{\mathrm{f}}=2.5$ (the original pattern is the right middle one in Fig. 3). Solid black lines denote fractures and grey patches represent landscape. The patch size is 0.78 times the minimum fracture length $l_{\min }$

covered by fractal landscape patterns (i.e. $D_{1}=1.5$ or 1.75), especially when the coverage ratio is high. This is attributed to the fact that space-filling landscape patches tend to trim more fractures, while fractally distributed landscape patches tend to form clustered coverage that creates higher lacunarity (exact counterpart of clustering) in the system and thus allows some larger fractures being preserved. Furthermore, the influence of landscape coverage on $a_{\mathrm{m}}$ is more significant for fracture networks having a small underlying length exponent $a_{\mathrm{f}}$ (see the large landscape-induced deviation of $a_{\mathrm{m}}$ from $a_{\mathrm{f}}$ when $a_{\mathrm{f}}=1.5$ in Fig. 7). This is because, when $a_{\mathrm{f}}$ is small, the system is more dominated by large fractures, which are more inclined to be affected by groundcover. The influence of $D_{\mathrm{f}}$ on $a_{\mathrm{m}}$ seems to be minor, suggesting 

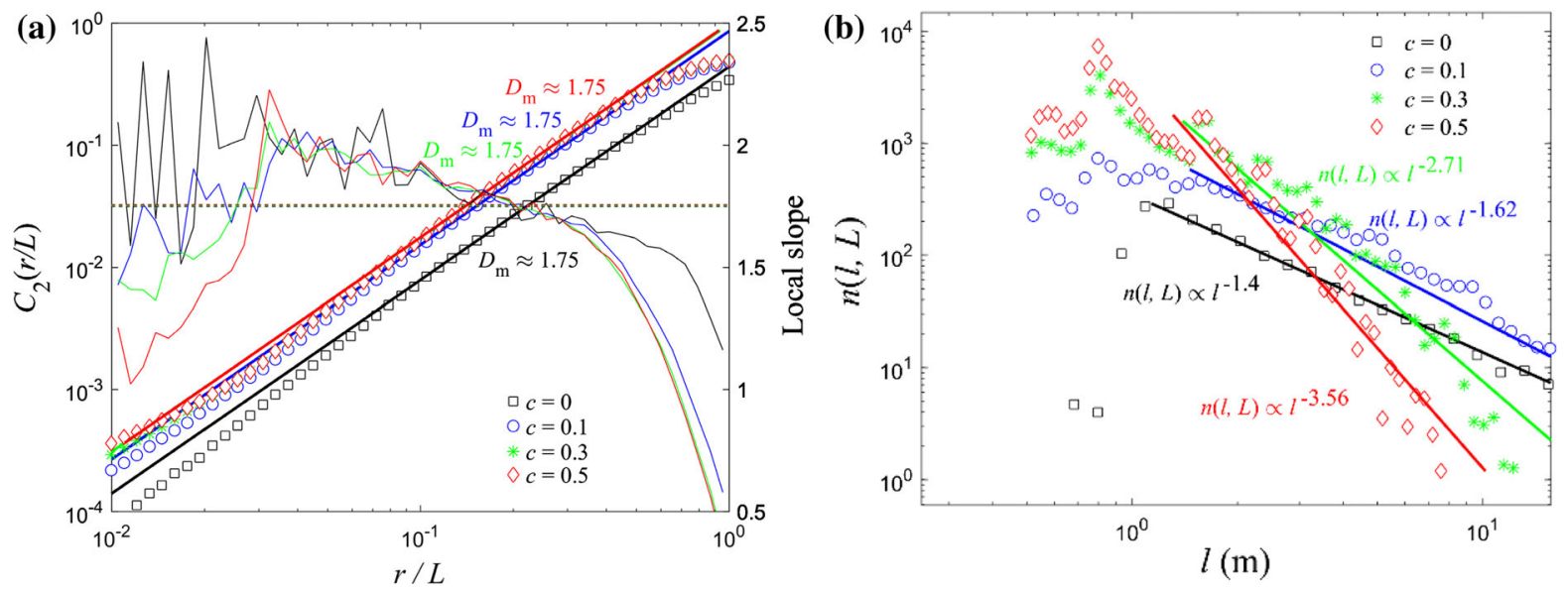

Figure 5

Measurement of the statistical properties of a fracture network pattern with an underlying fractal dimension $D_{\mathrm{f}}=1.75$ and a length exponent $a_{\mathrm{f}}=1.5$, before and after being covered by landscape patches with $D_{1}=2$ : a the normalised correlation function $C_{2}(r / L)$ for calculating the fractal dimension $D_{\mathrm{m}}$, and $\mathbf{b}$ the density distribution of fracture lengths for deriving the power law length exponent $a_{\mathrm{m}}$

that the measured size scaling of landscape-covered fracture networks may be independent of the underlying spatial characteristics of the fracture networks.

\section{Discussion}

In this paper, we explored the effects of landscape coverage on measuring the spatial and length properties of landscape-affected fracture networks for scenarios of different fracture network parameters (fractal dimension $D_{\mathrm{f}}$ and length exponent $a_{\mathrm{f}}$ ) and landscape spatial distribution parameters (fractal dimension $D_{1}$ and coverage rate $c$ ). The results have important implications for assessment of the statistical parameters derived based on natural fracture outcrops. To conduct field mapping, great efforts were often devoted to search sites with good quality exposures to keep them to a large extent free of vegetation (Odling 1997; Odling et al. 1999; Belayneh and Cosgrove 2004). However, in some geological sites, it can be very difficult to avoid the groundcover effects, because embryophytes can form vegetation on the Earth's surface over different length scales, making the mapped outcrop containing unknown gap zones (Ghosh and Daemen 1993; Rawnsley et al. 1998; Gillespie et al. 2001; Bisdom et al. 2017). Especially for aerial photograph-based mapping, small-scale fractures can be easily hidden by forests (Lei and Wang 2016). We thus suggest that when conducting field mapping, the distribution of vegetation should also be measured and characterised, especially when the landscape occupies more than $10 \%$ of the sampling region. Based on the landscape pattern parameters, the uncertainty of the measured statistical properties from mapped fracture networks can be further assessed and the underlying fractal dimension and length exponent may be recovered. Specifically, $D_{\mathrm{f}}$ may be first estimated based on $D_{1}$ and $c$ derived from field mapping. Then, synthetic fracture networks associated with the $D_{\mathrm{f}}$ value and a range of potential $a_{\mathrm{f}}$ values can be generated, which are further covered by landscape patches conditioned with the measured $D_{1}$ and $c$. The actual $a_{\mathrm{f}}$ value may, therefore, be found if the $a_{\mathrm{m}}$ value of the simulated landscape-covered fracture pattern matches that of the field outcrop. It is worth mentioning that multiple solutions to $a_{\mathrm{f}}$ may exist due to the complex nature of this inverse problem. Thus, a confidence interval may also need to be derived for the estimated $a_{\mathrm{f}}$ value.

The results from our research suggest that landscape spatial distribution may have minor effect on measuring the fractal dimension, but can cause significant biases in deriving the length exponent. Such vegetation-induced biases may also be a factor that 

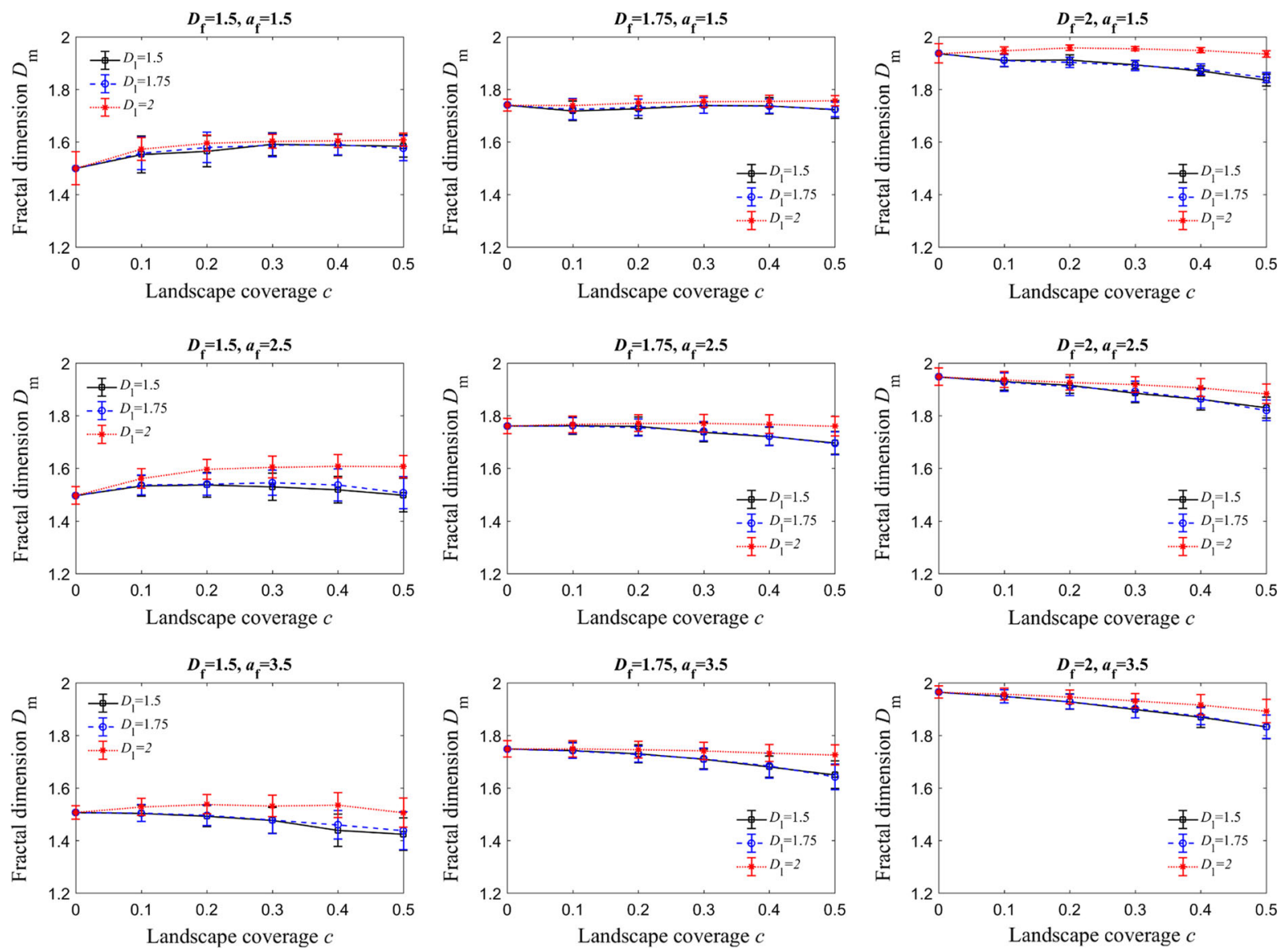

Figure 6

Measured fractal dimension $D_{\mathrm{m}}$ of landscape-covered fracture network patterns associated with different combinations of underlying fractal dimension $D_{\mathrm{f}}$ and length exponent $a_{\mathrm{f}}$, and different landscape fractal dimension $D_{1}$ and coverage ratio $c$

contributes to the observed inconsistency of power law scaling of fracture lengths over different length scales (Nicol et al. 1996; de Joussineau and Aydin 2007; Davy et al. 2010). Actually we can also see from Fig. $5 \mathrm{~b}$ that the landscape coverage can lead to a curvature at the small scale in the density distribution of fracture lengths, which may be related to the socalled "truncation effect" (Pickering et al. 1995; Bonnet et al. 2001) that is always present in the length distribution plot of outcrop data (Davy 1993; Odling 1997; Odling et al. 1999; Bour et al. 2002; Davy et al. 2010; Le Garzic et al. 2011; Bertrand et al. 2015; Lei et al. 2015; Lei and Wang 2016).

In the present work, fractures in each synthetic network are assumed completely random in orientation, aiming to provide a preliminary understanding of the landscape cover effects on the measurement of fracture length and spatial properties. However, natural fracture networks in rock can often be highly anisotropic consisting of multiple fracture sets each linked to separate formation stage. Thus, analysing the vegetation cover effects on the measurement of anisotropic fracture networks will be a focus of our future work. Furthermore, in the fracture network model, we represented fracture traces as 1D lines of the same width without taking into account the variation of fracture apertures, which may scale with fracture length following a power law (Vermilye and Scholz 1995; Renshaw and Park 1997; Bonnet et al. 2001; Olson 2003; Neuman 2008). Very large faults with wide apertures/damage zone thickness tend to be more observable and less affected by landscape 

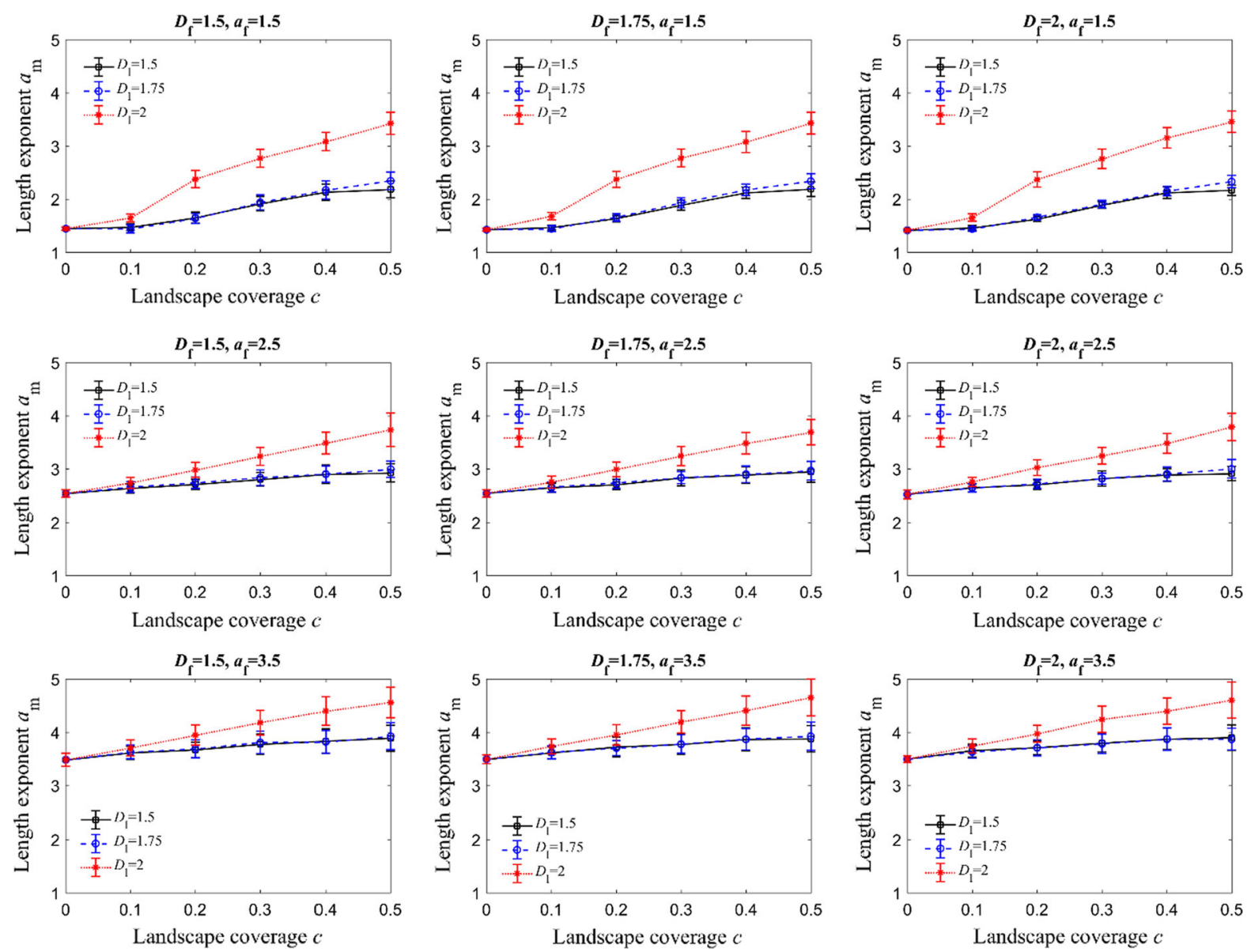

Figure 7

Measured length exponent $a_{\mathrm{m}}$ of landscape-covered fracture network patterns associated with different combinations of underlying fractal dimension $D_{\mathrm{f}}$ and length exponent $a_{\mathrm{f}}$, and different landscape fractal dimension $D_{1}$ and coverage ratio $c$

patches than small-scale fractures. It is worth mentioning that the current model also assumed that fracture network parameters are independent of landscape parameters. However, the tectonism that is related to the formation of superimposed fracture sets can also have a profound effect on landscape evolution (Lifton and Chase 1992; Kinast et al. 2016). A high fractal dimension of landscape is usually found in the region under a very low uplift rate, which allows fully downcut by erosive streamflows, while a low fractal dimension of vegetation often occurs in the tectonic system with a high uplift rate due to the limited degradation time of landscapes (Lifton and Chase 1992). This implies that a correlation between fracture network and landscape spatial distribution patterns may exist, which needs further investigation in the future.

\section{Conclusions}

To conclude, the influence of landscape coverage on the measurement of statistical properties of nature fracture networks was studied. Multiple realisations of synthetic fracture networks governed by the underlying fractal dimension and length exponent were generated, which were then superimposed by landscape maps with different coverage ratios and clustering features. By comparing the landscapecovered fracture network properties with their 
underlying ones, we found that landscape cover has a minor impact on the fractal dimension measurement, while the length exponent tends to be overestimated and a high discrepancy can occur in a fracture system dominated by large fractures (i.e. a small underlying length exponent), which are covered by space-filling landscape patches with a high coverage ratio. The research findings of this paper have important implications for field mapping and statistical analysis of geological systems.

Open Access This article is distributed under the terms of the Creative Commons Attribution 4.0 International License (http://creativecommons.org/licenses/by/4.0/), which permits unrestricted use, distribution, and reproduction in any medium, provided you give appropriate credit to the original author(s) and the source, provide a link to the Creative Commons license, and indicate if changes were made.

\section{REFERENCES}

Allegre, C. J., Le Mouel, J. L., \& Provost, A. (1982). Scaling rules in rock fracture and possible implications for earthquake prediction. Nature, 297, 47-49.

Barton, C. C. (1995). Fractal analysis of scaling and spatial clustering of fractures. In C. C. Barton \& P. R. La Pointe (Eds.), Fractals in the earth sciences (pp. 141-178). New York: Springer.

Belayneh, M., \& Cosgrove, J. W. (2004). Fracture-pattern variations around a major fold and their implications regarding fracture prediction using limited data: An example from the Bristol Channel Basin. In J. W. Cosgrove \& T. Engelder (Eds.), The initiation, propagation, and arrest of joints and other fractures (pp. 89-102). London: Geological Society, London, Special Publications.

Belayneh, M. W., Matthai, S. K., Blunt, M. J., \& Rogers, S. F. (2009). Comparison of deterministic with stochastic fracture models in water-flooding numerical simulations. American Association of Petroleum Geologists Bulletin, 93, 1633-1648.

Bemis, S. P., Micklethwaite, S., Turner, D., James, M. R., Akciz, S., Thiele, S. T., et al. (2014). Ground-based and UAV-based photogrammetry: A multi-scale, high-resolution mapping tool for structural geology and paleoseismology. Journal of Structural Geology, 69, 163-178.

Bertrand, L., Géraud, Y., Le Garzic, E., Place, J., Diraison, M., Walter, B., et al. (2015). A multiscale analysis of a fracture pattern in granite: A case study of the Tamariu granite, Catalunya, Spain. Journal of Structural Geology, 78, 52-66.

Bisdom, K., Bertotti, G., \& Bezerra, F. H. (2017). Inter-well scale natural fracture geometry and permeability variations in lowdeformation carbonate rocks. Journal of Structural Geology, 97, 23-36.

Bonnet, E., Bour, O., Odling, N. E., Davy, P., Main, I., Cowie, P., et al. (2001). Scaling of fracture systems in geological media. Review of Geophysics, 39, 347-383.
Bour, O., \& Davy, P. (1999). Clustering and size distributions of fault patterns: Theory and measurements. Geophysical Research Letters, 26, 2001-2004.

Bour, O., Davy, P., Darcel, C., \& Odling, N. (2002). A statistical scaling model for fracture network geometry, with validation on a multiscale mapping of a joint network. Journal of Geophysical Research, 107, ETG4-1-ETG4-12.

Cawood, A. J., Bond, C. E., Howell, J. A., Butler, R. W. H., \& Totake, Y. (2017). LiDAR, UAV or compass-clinometer? Accuracy, coverage and the effects on structural models. Journal of Structural Geology, 98, 67-82.

Chilès, J. P. (1988). Fractal and geostatistical methods for modeling of a fracture network. Mathematical Geosciences, 20, 631-654.

Clapuyt, F., Vanacker, V., \& Van Oost, K. (2016). Reproducibility of UAV-based earth topography reconstructions based on Structure-from-Motion algorithms. Geomorphology, 260, 4-15.

Darcel, C., Bour, O., Davy, P., \& de Dreuzy, J.-R. (2003). Connectivity properties of two-dimensional fracture networks with stochastic fractal correlation. Water Resources Research, 39, $1-13$.

Davy, P. (1993). On the frequency-length distribution of the San Andreas Fault System. Journal of Geophysical Research, 98, 12141-12151.

Davy, P., Bour, O., de Dreuzy, J.-R., \& Darcel, C. (2006). Flow in multiscale fractal fracture networks. In G. Cello \& B. D. Malamud (Eds.), Fractal analysis for natural hazards (pp. 31-45). London: Geological Society, London, Special Publications.

Davy, P., Le Goc, R., Darcel, C., Bour, O., de Dreuzy, J.-R., \& Munier, R. (2010). A likely universal model of fracture scaling and its consequence for crustal hydromechanics. Journal of Geophysical Research, 115(B10), B10411.

de Dreuzy, J., Darcel, C., Davy, P., \& Bour, O. (2004). Influence of spatial correlation of fracture centers on the permeability of twodimensional fracture networks following a power law length distribution. Water Resources Research, 40, 1-11.

de Joussineau, G., \& Aydin, A. (2007). The evolution of the damage zone with fault growth in sandstone and its multiscale characteristics. Journal of Geophysical Research, 112, B12401.

Eardley, A. J. (1942). Aerial photographs: Their use and interpretation. New York: Harper and Brothers.

Ehlen, J. (2000). Fractal analysis of joint patterns in granite. International Journal of Rock Mechanics and Mining Sciences, 37, 909-922.

Gardner, R. H., Milne, B. T., Turner, M. G., \& O’Neill, R. V. (1987). Neutral models for the analysis of broad scale landscape pattern. Landscape Ecology, 1, 19-28.

Ghosh, A., \& Daemen, J. J. K. (1993). Fractal characteristics of rock discontinuities. Engineering Geology, 34, 1-9.

Gillespie, P. A., Walsh, J. J., Watterson, J., Bonson, C. G., \& Manzocchi, T. (2001). Scaling relationships of joint and vein arrays from The Burren, Co., Clare, Ireland. Journal of Structural Geology, 23, 183-201.

Hentschel, H. G. E., \& Procaccia, I. (1983). The infinite number of generalized dimensions of fractals and strange attractors. Physica D: Nonlinear Phenomena, 8, 435-444.

Holland, M., Urai, J. L., Muchez, P., \& Willemse, E. J. M. (2009). Evolution of fractures in a highly dynamic thermal, hydraulic, and mechanical system-(I) field observations in Mesozoic Carbonates, Jabal Shams, Oman Mountains. GeoArabia, 14, 57-110. 
Kinast, S., Ashkenazy, Y., \& Meron, E. (2016). A coupled vegetation-crust model for patchy landscapes. Pure and Applied Geophysics, 173, 983-993.

Krummel, J. R., Gardner, R. H., Sugihara, G., O'Neill, R. V., \& Coleman, P. R. (1987). Landscape patterns in a disturbed environment. Oikos, 48, 325-335.

Kubo, T., Iwasa, Y., \& Furumoto, N. (1996). Forest spatial dynamics with gap expansion: Total gap area and gap size distribution. Journal of Theoretical Biology, 180, 229-246.

La Pointe, P. R. (1988). A method to characterize fracture density and connectivity through fractal geometry. International Journal Rock Mechanics and Mining Sciences \& Geomechanics Abstracts, 25, 421-429.

Le Garzic, E., de L'Hamaide, T., Diraison, M., Géraud, Y., Sausse, J., de Urreiztieta, M., et al. (2011). Scaling and geometric properties of extensional fracture systems in the proterozoic basement of Yemen. Tectonic interpretation and fluid flow implications. Journal of Structural Geology, 33(4), 519-536.

Lei, Q., Latham, J.-P., \& Tsang, C.-F. (2017). The use of discrete fracture networks for modelling coupled geomechanical and hydrological behaviour of fractured rocks. Computers and Geotechnics, 85, 151-176.

Lei, Q., Latham, J.-P., Tsang, C.-F., Xiang, J., \& Lang, P. (2015). A new approach to upscaling fracture network models while preserving geostatistical and geomechanical characteristics. Journal of Geophysical Research: Solid Earth, 120, 4784-4807.

Lei, Q., \& Wang, X. (2016). Tectonic interpretation of the connectivity of a multiscale fracture system in limestone. Geophysical Research Letters, 43, 1551-1558.

Lifton, N. A., \& Chase, C. G. (1992). Tectonic, climatic and lithologic influences on landscape fractal dimension and hypsometry: Implications for landscape evolution in the San Gabriel Mountains, California. Geomorphology, 5, 77-114.

Maerten, L., Pollard, D. D., \& Maerten, F. (2001). Digital mapping of three-dimensional structures of the Chimney Rock fault system, central Utah. Journal of Structural Geology, 23, 585-592.

Mandelbrot, B. B., \& Pignoni, R. (1983). The fractal geometry of nature. New York: WH freeman.

Milne, B. T., Johnston, K. M., \& Forman, R. T. T. (1989). Scaledependent proximity of wildlife habitat in a spatially-neutral Bayesian model. Landscape Ecology, 2, 101-110.

Neuman, S. P. (2008). Multiscale relationships between fracture length, aperture, density and permeability. Geophysical Research Letters, 35, L22402.

Nicol, A., Walsh, J. J., Watterson, J., \& Gillespie, P. A. (1996). Fault size distributions-are they really power-law? Journal of Structural Geology, 18, 191-197.

Odling, N. E. (1992). Network properties of a two-dimensional natural fracture pattern. Pure and Applied Geophysics, 138, 95-114.

Odling, N. E. (1997). Scaling and connectivity of joint systems in sandstones from western Norway. Journal of Structural Geology, 19, 1257-1271.
Odling, N. E., Gillespie, P., Bourgine, B., Castaing, C., Chilés, J.P., Christensen, N. P., et al. (1999). Variations in fracture system geometry and their implications for fluid flow in fractured hydrocarbon reservoirs. Petroleum Geoscience, 5, 373-384.

Olson, J. E. (2003). Sublinear scaling of fracture aperture versus length: An exception or the rule? Journal of Geophysical Research, 108, 2413.

Pickering, G., Bull, J. M., \& Sanderson, D. J. (1995). Sampling power-law distributions. Tectonophysics, 248, 1-20.

Pillmore, C. L. (1957). Application of high-order stereoscopic plotting instruments to photogeologic studies. Washington D. C.: Geological Survey Bulletin.

Rawnsley, K. D., Peacock, D. C. P., Rives, T., \& Petit, J. P. (1998). Joints in the Mesozoic sediments around the Bristol Channel Basin. Journal of Structural Geology, 20, 1641-1661.

Ray, R. G. (1984). Aerial photographs in geologic interpretation and mapping. Washington D. C.: Geological Survey Professional Paper.

Reed, J. (1940). The use of airplane photographs in the geologic study of the Chichagof mining district, Alaska. Photogrammetric Engineering, 6, 35-44.

Renshaw, C. E., \& Park, J. C. (1997). Effect of mechanical interactions on the scaling of fracture length and aperture. Nature, 386, 482-484.

Rutqvist, J., \& Stephansson, O. (2003). The role of hydromechanical coupling in fractured rock engineering. Hydrogeology Journal, 11, 7-40.

Smith, J. S., Chandler, J., \& Rose, J. (2009). High spatial resolution data acquisition for the geosciences: Kite aerial photography. Earth Surface Processes and Landforms, 34, 155-161.

Turner, M. G., Gardner, R. H., Dale, V. H., \& O’Neill, R. V. (1989). Predicting the spread of disturbance across heterogeneous landscapes. Oikos, 55, 121-129.

Turner, M. G., Gardner, R. H., \& O’Neill, R. V. (2001). Landscape ecology in theory and practice. New York: Springer.

Turner, M. G., \& Rusher, C. L. (1988). Changes in landscape patterns in Georgia, USA. Landscape Ecology, 1, 241-251.

Vermilye, J. M., \& Scholz, C. H. (1995). Relation between vein length and aperture. Journal of Structural Geology, 17, 423-434.

Vollgger, S. A., \& Cruden, A. R. (2016). Mapping folds and fractures in basement and cover rocks using UAV photogrammetry, Cape Liptrap and Cape Paterson, Victoria, Australia. Journal of Structural Geology, 85, 168-187.

Watkins, H., Bond, C. E., Healy, D., \& Butler, R. W. H. (2015). Appraisal of fracture sampling methods and a new work flow to characterise heterogeneous fracture networks at outcrop. Journal of Structural Geology, 72, 67-82.

Wu, J., Jelinski, D. E., Luck, M., \& Tueller, P. T. (2000). Multiscale analysis of landscape heterogeneity: Scale variance and pattern metrics. Geographic Information Sciences, 6, 6-19.

Xu, T., Moore, I. D., \& Gallant, J. C. (1993). Fractals, fractal dimensions and landscapes-a review. Geomorphology, 8, 245-262.

(Received September 16, 2017, revised December 23, 2017, accepted January 5, 2018, Published online January 13, 2018) 